\title{
Manejo de plagas de árboles frutales deciduos durante el invierno
}

PAMELA M. GEISEL, Coordinadora Académica, Programa Estatal Jardineros Maestros de la Universidad de California; y DONNA C. SEAVER, Representante del Programa, Programa Estatal Jardineros Maestros de la Universidad de California. Originalmente publicado como Winter Pest Management in Backyard Deciduous Fruit Trees (ANR Publication 8368).

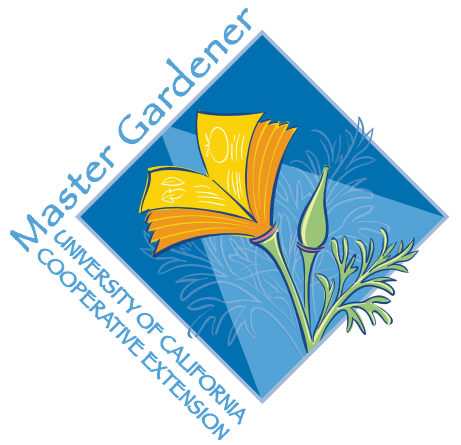

Todos los árboles frutales deciduos son susceptibles a plagas e insectos que afectan la calidad de la fruta y la salud del árbol. La época latente de invierno, que ocurre después de que las hojas se caen pero antes de que las yemas broten en la primavera, es el mejor momento para manejar varios problemas. Prácticas claves durante esta época del año son

- podar para quitar ramas muertas, enfermas y quebradas, promover vigor, abrir la copa del árbol al sol y mejorar la circulación del aire

- tomar medidas de salubridad para quitar fruta momificada en el árbol, y madera enferma, fruta y hojas del suelo

- aplicar aerosoles latentes de aceite para controlar las plagas

- aplicar aerosoles latentes o latentes retrasados para limitar la infección y prevenir la propagación de algunas enfermedades

\section{LA PODA}

La ausencia de hojas durante el invierno brinda una vista clara de la estructura del árbol y la oportunidad de podar quitando completamente o sólo la punta de algunas ramas. Se tendrá que podar menos durante la época latente si los árboles han sido podados y entrenados apropiadamente en el verano. Para controlar plagas y enfermedades, pode ramas muertas, enfermas, cruzadas o quebradas, al igual que chupones que brotan del tronco o raíces. Quite y destruya toda la madera enferma.

Desinfecte regularmente las herramientas de poda con un desinfectante o una mezcla de 1:1 blanqueador y agua durante la poda y siempre que las herramientas entren en contacto con madera enferma. Lubrique con aceite las tijeras podadoras inmediatamente después de usarlas para prevenir la corrosión. 
Pinte el tronco y las ramas inferiores de árboles jóvenes que estén expuestos al sol de la tarde con una mezcla de 1:1 pintura blanca látex para interiores y agua para prevenir lesiones por quemaduras y reducir infestaciones de barrenadores. Aplique la mezcla de pintura comenzando a dos pulgadas (5.1 $\mathrm{cm})$ debajo de la línea del suelo y hasta alcanzar una altura de 2 pies $(61 \mathrm{~cm})$.

\section{SALUBRIDAD}

Buenas medidas de salubridad son necesarias para prevenir enfermedades y plagas y para reducir la necesidad de fumigaciones. Si es posible, recoja con un rastrillo todas las hojas y bótelas después de que se caigan y antes de las primeras lluvias. Quite y destruya fruta momificada que quede en el árbol y en el suelo durante el invierno para eliminar fuentes de insectos y enfermedades para la próxima temporada.

\section{FuMIGACIÓN CON AEROSOLES LATENTES O LATENTES RETRASADOS}

Los aerosoles latentes o aerosoles latentes retrasados son términos generales para la aplicación de pesticidas-inclusive aceites hortícolas muy refinados, aceites combinados con un pesticidacuando los árboles están latentes o las yemas están comenzando a hincharse. La aplicación de aerosoles latentes provee un tratamiento económico y eficaz contra varias enfermedades e insectos que pasan el invierno en los árboles como

- la cochinilla (San José, conchuela café europea, etc.) - en muchas especies de árboles frutales

- huevos de ácaros europeos rojos y morenos - en frutales de hueso y peras

- el perforador del duraznero (sólo cuando se combina con un insecticida como Spinosad) - en albaricoque, nectarina y durazno, a veces ciruela, y ciruela pasa

- el ácaro del peral - en peras

- la pulguilla del peral - en peras

- los huevos de áfidos - en muchas especies de árboles frutales

- El torque de hoja (hongo) - en nectarina y durazno

- El barrenillo (hongo) - en albaricoque, nectarina y durazno

Los aceites utilizados durante esta época incluyen: aceites insecticidas, de rango limitado, supremo o aceites tipo superior. Una fumigación con aceite supremo o tipo superior, aplicada durante el periodo latente retrasado, justo cuando los huevos están a punto de abrirse, debe mantener la población de ácaros europeos rojos y morenos en un nivel que no sea dañino si los depredadores no son perturbados por fumigaciones contra otros insectos. Los aceites supremos o de tipo superior matarán los huevos de áfidos que pasan el invierno en los árboles frutales si se les aplica tarde en el periodo latente cuando los huevos comienzan a abrirse al comenzar la primavera. Estos tratamientos no controlarán totalmente los áfidos y probablemente no se justifican sólo para controlar los áfidos.

Las fumigaciones con aceites en el periodo latente, por sí solas, NO CONTROLAN la polilla oriental del duraznero, el gusano del naranjo, el perforador del duraznero, o ácaros comunes o rojos y la arañita del Pacífico.

Las aplicaciones durante el periodo latente para controlar enfermedades utilizan materiales como cobre, cal azufre (poli sulfito de calcio), caldo bordolés (Bordeaux) (una mezcla de cobre en polvo y cal hidratada) o un fungicida sintética para limitar la infección y prevenir la propagación de ciertas enfermedades de hongos, como el torque de hoja, el barrenillo, mildiu polvoriento y sarna.

\section{Aplicación de tratamientos latentes o latentes retrasados}

Un tratamiento latente no siempre es necesario cada año en el huerto, excepto donde el torque del duraznero es un problema constante. Decida si debe aplicar el tratamiento fijándose en qué tan extenso fue el daño causado por insectos y enfermedades el año anterior.

Aplique al comienzo del periodo latente a fines de noviembre hasta tarde en el periodo latente, justo antes de que se abran las yemas (hinchazón de yemas) en febrero o al comienzo de marzo. El momento exacto durante la época latente puede variar dependiendo de la enfermedad que está controlando. Una vez que las yemas comienzan a abrirse, usted corre el riesgo de dañar la fruta y matar las abejas polinizadoras con algunos insecticidas.

El fumigar después de podar permite la máxima cobertura del árbol puesto que no hay hojas que bloqueen la fumigación. Se pueden usar bombas manuales o bombas de aire comprimido para fumigar. Evite tratar árboles estresados por falta de agua para no lesionarlos. 
Un buen momento para fumigar es inmediatamente después de que haya llovido o haya habido neblina. No fumigue cuando esté lloviendo, haya neblina o durante o antes de una helada (temperaturas por debajo de $32^{\circ} \mathrm{F}\left[0^{\circ} \mathrm{C}\right]$ ). Para evitar daño a árboles deciduos, no se debe aplicar aceite en un periodo de 30 días antes o después de aplicar azufre u otros fungicidas. Los aceites usualmente no son recomendables durante la época latente para árboles de nuez. Siempre lea la etiqueta cuidadosamente para saber las restricciones y siga las instrucciones de uso del producto.

Los fungicidas de cobre fijo contienen una forma de cobre elemental, como sulfato de cobre tribásico, sulfato de oxicloruro de cobre o hidróxido cúprico. Para algunas enfermedades podría ser necesario hacer varias aplicaciones para proteger brotes y flores emergentes, especialmente durante temporadas lluviosas. Para evitar decoloración de las frutas, no aplique compuestos de cobre después de la floración.

La cal azufre (poli sulfato de calcio) se recomienda menos para una fumigación latente de uso general, pero es muy útil para el problema de sarna en manzanos o perales cuando se le aplica justo cuando se hinchan las yemas. Cal azufre y otros compuestos que contienen azufre no se deben aplicar antes de que pasen 3 semanas desde que se aplicara aceite; sino se puede causar daño al árbol. Evite el uso de cal azufre en árboles de albaricoque, los cuales son muy sensibles al azufre.

El caldo bordolés (Bordeaux) es una mezcla de sulfato de cobre, cal hidratada y agua. El caldo bordolés ha sido un fungicida y bactericida excelente que se ha utilizado por muchas décadas principalmente porque persiste en los árboles y resiste las lluvias invernales. Sin embargo, requiere una preparación cuidadosa, toma más tiempo mezclarlo, mancha las superficies de color azul y no es compatible con otros pesticidas. Actualmente no hay productos premezclados de caldo bordolés registrados en California. Además, ningún producto de cal está registrado para mezclarlo con cobre para preparar el caldo bordolés.

No siempre se requieren tratamientos durante la época latente. Para algunos insectos y enfermedades, un tratamiento con buena cobertura podría ser suficiente. Para otros problemas y dependiendo de la gravedad de la plaga, podrían ser necesarias hasta tres aplicaciones para un control adecuado. Decida si merece una aplicación y cuantas veces se necesita, fijándose en la cantidad de insectos y enfermedades el año anterior.

\section{Albaricoque}

- Pode para que las ramas bajas den fruto. Pode las ramas muertas, enfermas, cruzadas o quebradas. Pode ramas para que entre luz y aire a la copa y así asegurar buena cobertura de las fumigaciones. Evite cortes que despuntan las ramas, con la excepción de árboles jóvenes. Algunas cortes que despuntan ramas podrían ser apropiados si está tratando de establecer ramas donde hay un hueco.

- Para controlar la cochinilla San José, ácaros o huevos de áfidos, fumigue los árboles completamente con aceite latente, incluyendo el tronco, justo antes de que broten las yemas.

- Antes de que comiencen las lluvias, quite y destruya toda fruta momificada en las ramas para reducir la podredumbre parda.

- Aplique fungicida de cobre fijo durante o justo después de la caída de las hojas, pero antes de que comiencen las lluvias del invierno si el hongo del barrenillo ha sido un problema durante los meses anteriores.

\section{- Precauciones:}

- No utilice productos a base de azufre para fumigar árboles de albaricoque.

- Para prevenir infección por el hongo de la eutopiosis, el cual se propaga con las lluvias, pode los árboles de albaricoque por lo menos 6 semanas antes de que comiencen las lluvias o después de la época de lluvia.

\section{Cerezo}

- Pode para mantener el árbol a una altura conveniente para cuidarlo. Quite ramas muertas, enfermas, cruzadas o quebradas. Pode aproximadamente un 10 por ciento del crecimiento del año previo en los árboles maduros para que entre luz y aire y así asegurar una buena cobertura con las fumigaciones.

- Fumigue los árboles completamente, incluyendo el tronco, con aceite latente tarde en la época latente, y justo antes de que se abran las yemas, para controlar cochinillas, huevos de ácaro y áfidos.

\section{Duraznero y Nectarinero}

- Pode para mantener el árbol a una altura conveniente para cuidarlo. Quite ramas muertas, enfermas, cruzadas o quebradas. Pode más o menos 
la mitad del crecimiento del año anterior para ralear la producción y asegurar que entre luz y aire y haya una buena cobertura con las fumigaciones.

- Pode más las variedades que producen fruta temprano que las variedades que maduran más tarde.

- Fumigue los árboles completamente, incluyendo el tronco, con aceite latente tarde en la época latente, justo antes de que se abran las yemas, para controlar la cochinilla y huevos de ácaro.

- Quite y destruya toda fruta momificada en las ramas para reducir plagas en el futuro.

- Fumigue con una fungicida de cobre dos veces para controlar el torque del duraznero y el barrenillo, la primera vez alrededor del 15 de noviembre o después de que hayan caído las hojas, y luego en la primera mitad de febrero. La segunda fumigación debe hacerse cuando las yemas se están hinchando, pero antes de que se abran las flores.

\section{Ciruelo (incluyendo cherry plum, pluot y ciruela pasa)}

- Quite ramas muertas, enfermas, cruzadas o quebradas. Pode más o menos el 20 por ciento del crecimiento del año previo para que entre luz y aire a la copa y así asegurar una buena cobertura con las fumigaciones. Pode con cortes en las puntas de las ramas sólo en árboles inmaduros o donde quiera que brote una rama nueva.

- Fumigue los árboles completamente, incluyendo el tronco, con aceite latente tarde en la época latente, justo antes de que se abran las yemas, para controlar la cochinilla San José, ácaros y huevos de áfidos. (Los aceites latentes no controlará los áfidos completamente.)

- Quite y destruya toda fruta momificada en las ramas para reducir la podredumbre parda.

\section{Frutales de pepita (manzano, peral y}

\section{membrillo)}

- Pode para mantener el árbol a una altura conveniente para cuidarlo. Pode más o menos entre el 15 y el 20 por ciento del crecimiento del año previo para que entre luz y aire a la copa para mantener una buena producción de fruta y asegurar una buena cobertura con las fumigaciones. Quite ramas muertas, enfermas, cruzadas o quebradas, al igual que chupones que brotan del tronco o raíces.
- Fumigue los árboles completamente, incluyendo el tronco, con aceite latente tarde en la época latente, justo antes de que se abran las yemas, para controlar la cochinilla, ácaros europeos rojos, ácaros del peral (sólo pera), áfidos y adultos de la pulguilla del peral (sólo pera).

- Fumigue con cal azufre (poli sulfito de calcio) durante la hinchazón de las yemas, pero antes de que se abran, para controlar sarna, ácaros del peral y adultos y huevos de la pulguilla del peral.

- Quite y destruya fruta momificada en el árbol o en el suelo durante el invierno para reducir la polilla del manzano y sarna. Quite y destruya hojas caídas para reducir infecciones de sarna la próxima primavera.

\section{ADVERTENCIA SOBRE EL USO DE PRODUCTOS QUÍMICOS}

Los pesticidas son venenosos. Siempre lea y siga cuidadosamente las precauciones y recomendaciones de seguridad en la etiqueta. Guarde los químicos en sus contenedores originales en un gabinete o bodega asegurada, aparte de comida o alimentos, y lejos del alcance de niños, personas no autorizadas, mascotas y ganado.

Limite los pesticidas a la propiedad que está siendo tratada. Evite desplazamiento hasta propiedades adyacentes o huertos que contienen frutas $y / 0$ verduras listas para cosechar.

Elimine los contenedores vacíos con cuidado. Siga las instrucciones de la etiqueta para eliminación. Nunca rehúse los contenedores. Asegure que los niños y animales no tengan acceso a los contenedores vacíos. Nunca bote los contenedores donde podrían contaminar a las fuentes de agua o vías de agua naturales. No vierta a los pesticidas al lavabo o al inodoro. Consulte al comisionado de agricultura de su condado para las maneras correctas de eliminar los pesticidas sobrantes. Nunca queme a los contenedores de pesticidas. INTOXICACIÓN DE LAS PLANTAS: Algunas químicos podrían causar daño a las plantas si están utilizadas durante una etapa incorrecta de desarrollo de las plantas o cuando las temperaturas están demasiadas altas. El uso de cantidades de pesticidas excesivas, formulaciones incorrectas o la mezcla de materiales no compatibles podría resultar en daño a las plantas también. Como los fabricantes de pesticidas cambian las formulaciones con frecuencia, es posible que daño a las plantas podría ocurrir, aunque ningún daño fue observado en años previos. 
Para mas información, contacte a los Jardineros Maestros locales o busque en línea: http://camastergardeners.ucdavis.edu.

Agradecemos el apoyo para este proyecto de Elvenia J. Slosson Research Endowment for Ornamental Horticulture. Se tomó parte del contenido usado en esta publicación del sitio web del Programa Estatal de Manejo Integrado de Plagas de la Universidad de California (http://www.ipm.ucdavis.edu/). Traducción al español: Andrew Kramer y Myriam Grajales-Hall. Diseño del póster: Will Suckow Ilustración.

Fotos: Jack Kelly Clark.

\section{RECURSOS EN LÍNEA}

\section{Sitios web}

\section{En español}

Consejos/sugerencias rápidas sobre insectos dañinos en el hogar y en el jardín

Áfidos o pulgones (Notas Breves) - http://ipm.ucdavis.edu/PDF/QTSP/qtspaphids.pdf

\section{En inglés}

\section{California Master Gardeners}

http://camastergardeners.ucdavis.edu/

\section{California Backyard Orchard}

http://homeorchard.ucdavis.edu

UC Statewide Integrated Pest Management Project - Pests in Gardens and Landscapes Fruit and Nuts

http://ipm.ucdavis.edu/PMG/GARDEN/fruit.html

\section{Publicaciones /Folletos}

\section{En inglés}

California Master Gardener Handbook

http://anrcatalog.ucdavis.edu/InOrder/Shop/ItemDetails.asp?ItemNo=3382

\section{Calendar of Operations for Home Gardeners}

Apples and Pears - http://anrcatalog.ucdavis.edu/pdf/7258.pdf

Apricots - http://anrcatalog.ucdavis.edu/pdf/7259.pdf

Cherries - http://anrcatalog.ucdavis.edu/pdf/7260.pdf

Peaches and Nectarines - http://anrcatalog.ucdavis.edu/pdf/7261.pdf

Plums - http://anrcatalog.ucdavis.edu/pdf/7262.pdf

\section{Dormant Sprays Defined}

http://ucce.ucdavis.edu/files/datastore/268-329.pdf

\section{Home Orchard}

ANR Publication 3485

http://anrcatalog.ucdavis.edu/InOrder/Shop/ItemDetails.asp?ItemNo=3485

Pests of the Garden and Small Farm - A Grower's Guide to Using Less Pesticide

ANR Publication 3332

http://anrcatalog.ucdavis.edu/InOrder/Shop/ItemDetails.asp?ItemNo=3332

UC IPM Pest Notes - Insects, Mites, etc.

Aphids (Pest Note) - http://ipm.ucdavis.edu/PDF/PESTNOTES/pnaphids.pdf Aphids (Quick tip) - http://ipm.ucdavis.edu/PDF/QT/qtaphids.pdf

Scale (Pest Note) - http://www.ipm.ucdavis.edu/PDF/PESTNOTES/pnscales.pdf

Scale (Quick Tip) - http://ipm.ucdavis.edu/PDF/QT/qtscales.pdf 
UC IPM Pest Notes - Pesticides and Other Management Methods

Bordeaux mixture - http://ipm.ucdavis.edu/PDF/PESTNOTES/pnbordeauxmixture.pdf

\author{
UC IPM Pest Notes - Plant Diseases
}

Apple Scab - http://ipm.ucdavis.edu/PDF/PESTNOTES/pnapplescab.pdf

Leaf Curl/Peach Leaf Curl - http://ipm.ucdavis.edu/PDF/PESTNOTES/pnleafcurl.pdf

\title{
INFORMACIÓN DE PEDIDOS
}

Si desea obtener esta publicación, visite el sitio web de ANR Communication Services (http://anrcatalog.ucdavis.edu) o póngase en contacto con:

University of California

Division of Agriculture and Natural Resources

Communication Services

6701 San Pablo Avenue, 2nd Floor

Oakland, California 94608-1239

Teléfono: 1-800-994-8849

(415) 642-2431

FAX: (510) 643-5470

E-mail: danrcs@ucdavis.edu

(C) En 2009 por los Regentes de la Universidad de California,

División de Agricultura y Recursos Naturales. Todos los derechos reservados.

Ninguna parte de esta publicación puede ser reproducida, almacenada en un sistema recuperable, o transmitida, de cualquier forma o por cualquier medio, electrónico, mecánico, de fotocopiado, grabación, u de otra manera, sin el permiso escrito del editor y los autores.

\section{Publicación 8368-S}

ISBN-13: 978-1-60107-668-7

La Universidad de California prohíbe la discriminación o el hostigamiento de cualquier persona por razones de raza, color, origen nacional, religión, sexo, identidad en función del género, embarazo (inclusive parto y condiciones médicas relacionadas con el embarazo o el parto), incapacidad física o mental, estado de salud (casos de cáncer o de características genéticas), ascendencia, estado civil, edad, preferencia sexual, ciudadanía o condición de veterano (veterano con incapacidad específica, veterano que se haya retirado del servicio recientemente, veterano de la era de Vietnam o cualquier veterano que haya estado en servicio activo en una guerra, campaña o expedición para la cual una insignia de campaña haya sido autorizada), en cualquiera de sus programas o actividades.
La política de la Universidad se propone concordar con las disposiciones de las leyes federales y estatales procedentes.

Las preguntas sobre la política antidiscriminatoria de la Universidad pueden dirigirse a: Affirmative Action/Staff Personnel Services Director, University of California, Agriculture and Natural Resources, 1111 Franklin St., 6th Floor, Oakland, CA 94607-5201, (510) 987-0096. Para obtener información acerca de cómo obtener esta publicación, llame al 1-800-994-8849.

Para simplificar la información, se han usado nombres comerciales de productos. No se intenta respaldar el producto mencionado o ilustrado, ni insinuar una crítica a productos similares que no se nombran o aparecen ilustrados.

Una versión electrónica de esta publicación está disponible en el sitio web de ANR Communication Services, http://anrcatalog. ucdavis.edu.

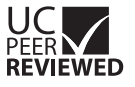

Esta publicación ha sido revisada anónimamente por científicos y especialistas de la Universidad de California y de otras instituciones para asegurar su contenido técnico. El proceso de revisión estuvo a cargo de los editores asociados para Control de Plagas-Urbano y para Publicaciones en Español de ANR.

web-09/09-LR/CR 


\section{Pregunte a un Jardinero Maestro de la UC \\ Manejo de plagas de árboles frutales deciduos durante el invierno}

El mejor tiempo para manejar varias plagas y enfermedades es durante el invierno cuando los árboles están latentes-después de que se caen las hojas pero antes de la yema rosada en la primavera.

\section{Cuatro etapas de la floración de la nectarina y el durazno}

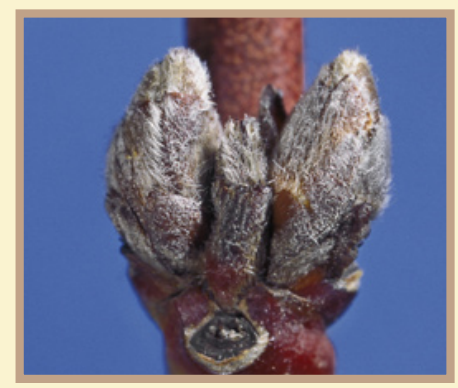

yema latente

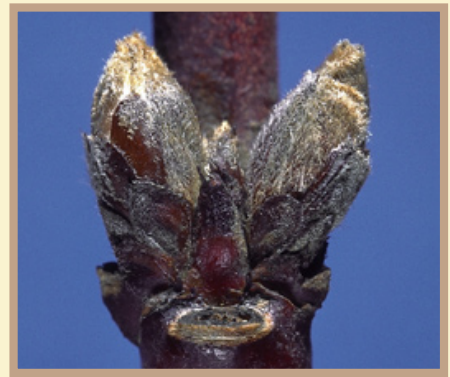

yema latente

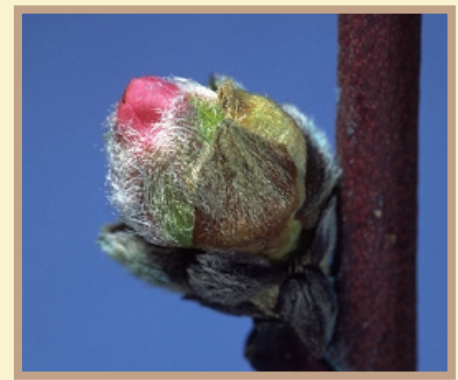

yema rosada

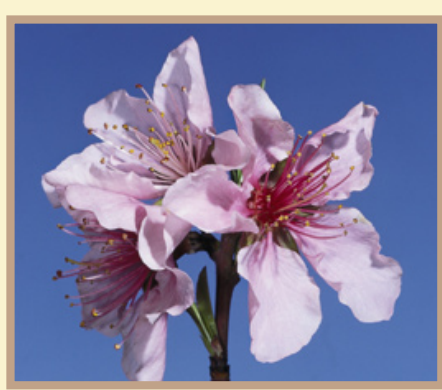

floración completa

Para más información, contacte a los Jardineros Maestros locales (http://camastergardeners.ucdavis.edu). Agradecemos el apoyo para este proyecto de Elvenia J. Slosson Research Endowment for Ornamental Horticulture. Parte del contenido de este documento fue extraído del sitio web del Programa de Manejo Integrado de Plagas de la UC (http://www.ipm.ucdavis.edu/).

Manejo del proyecto: Pamela M. Geisel; Donna C. Seaver. Traducción al español: Andrew Kramer y Myriam Grajales-Hall. Diseño del póster:Will Suckow Ilustración. Fotos: Jack Kelly Clark.

No se intenta respaldar los sitios, productos o información mencionada, ni insinuar una crítica a los no mencionados. La Universidad de California no discrimina en sus políticas, procedimientos o prácticas. La Universidad es una entidad de acción afirmativa/igualdad de oportunidad.

\section{ADVERTENCIA DEL USO DE QUÍMICOS}

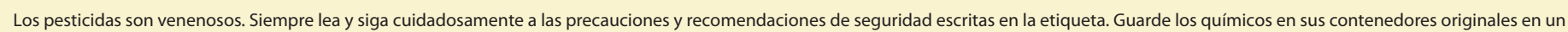
gabinete o bodega asegurada, aparte de comida o alimento, afuera del alcance de niños, personas no autorizadas, mascotas y ganado.

Limite los pesticidas a la propiedad que está siendo tratado. Evite desplazamiento hasta propiedades adyacentes o huertos que contienen frutas y/o verduras listas para cosechar.

Elimine los contenedores vacíos con cuidado. Siga las instrucciones de la etiqueta para eliminación. Nunca reuse los contenedores. Asegure que los niños y animales no tengan acceso a los contenedores vacíos. Nunca bote los contenedores donde podrían contaminar a las fuentes de agua o vías de agua naturales. No vierta a los pesticidas al lavabo o al inodoro. Consulte al comisionado de agricultura de su condado para las maneras correctas de eliminar los pesticidas sobrantes. Nunca queme a los contenedores de pesticidas.

INTOXICACIÓN DE LAS PLANTAS: Algunos químicos podrían causar daño a las plantas si están utilizadas durante una etapa incorrecta de desarrollo de las plantas o cuando las temperaturas están demasiadas altas. El uso de cantidades de pesticidas excesivas, formulaciones incorrectas o la mezcla de materiales no compatibles podría resultar en daño a las plantas también. Es posible que daño a las plantas podrían ocurrir, aunque ningún daño fue 


\section{Manejo de plagas de árboles}

\section{frutales deciduos durante el invierno}

\section{La poda e higiene son prácticas claves cuando árboles frutales están latentes.}

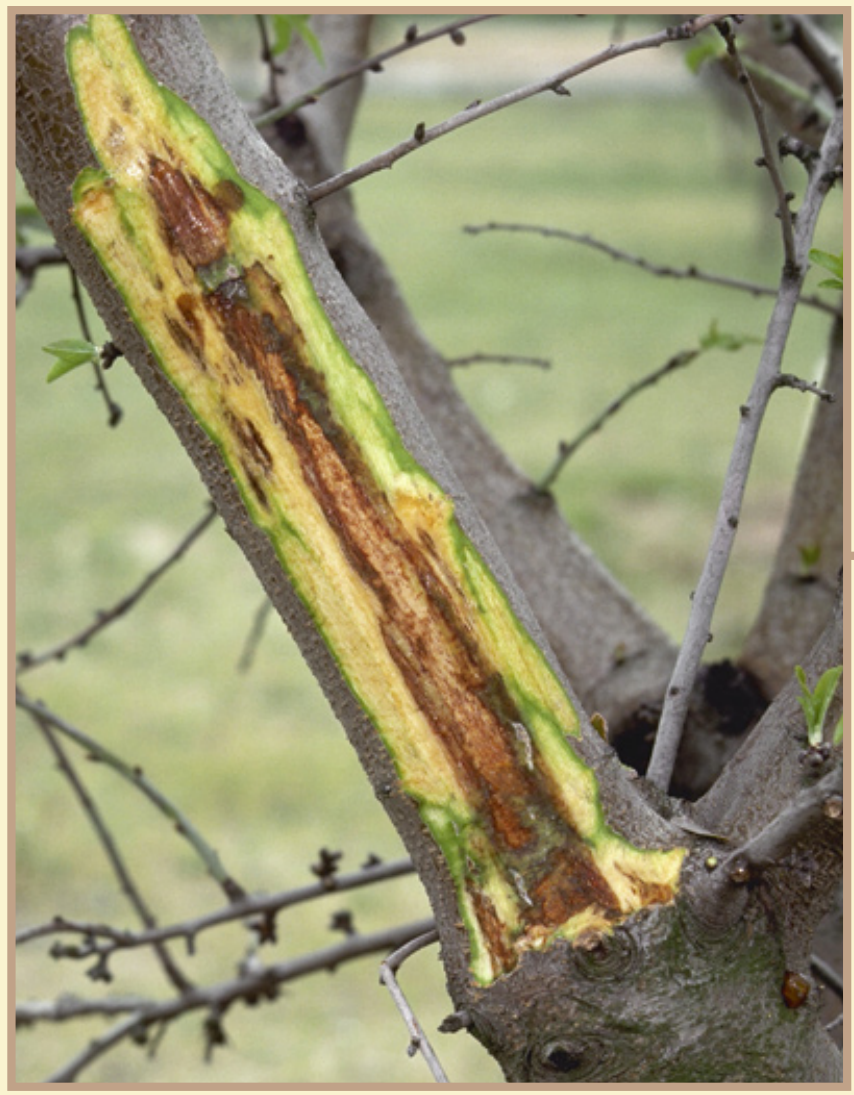

- Pode para quitar ramas muertas, enfermas, rotas o las que exudan líquido.

Cancro bacterial (mostrado, izquierda)

- Practique higiene quitando fruta momificada en los árboles y frutas y hojas caídas.

Fruta momificada, causada por putrefacción moreno, causa aumenta de enfermedades (mostrado, derecha)

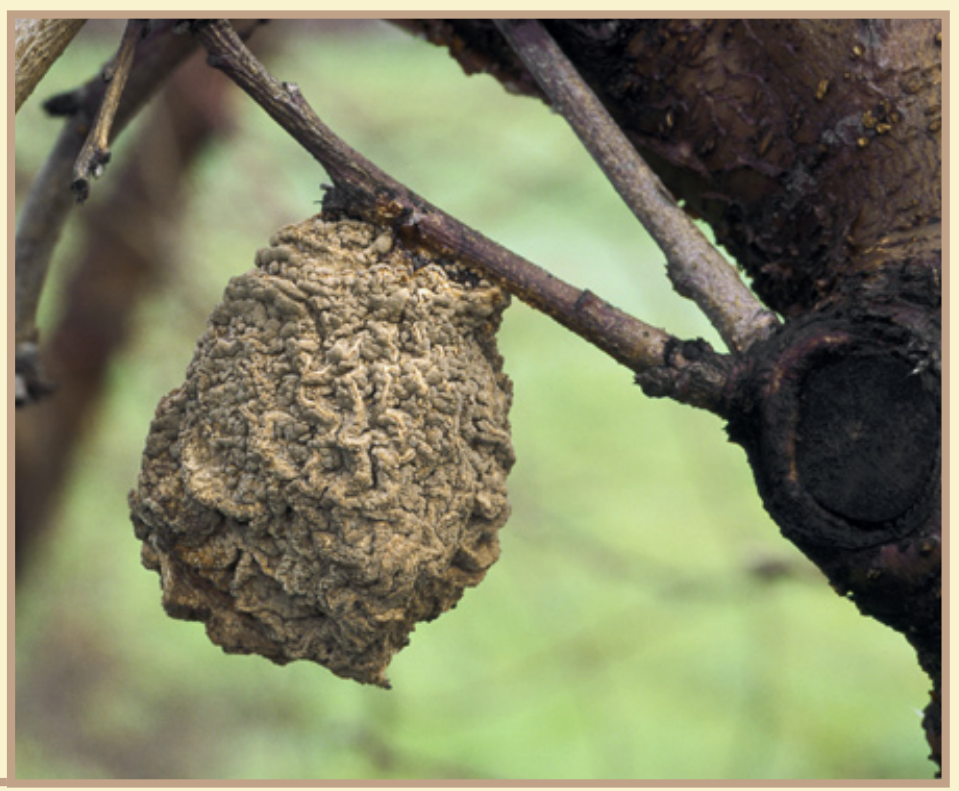




\section{Manejo de plagas de árboles}

\section{frutales deciduos durante el invierno}

\section{Aplique fumigaciones latentes-}

\section{el tiempo exacto durante la época}

latente puede variar dependiendo de

la enfermedad que está controlando.

- Fumigaciones

latentes y latentes

retrasadas de aceite controlan insectos.

Escama San José (mostrado,derecha) y la mayoría de escamas suaves; perforador de la ramita del duraznero (con insecticida); áfidos y los huevos del ácaro rojo y moreno europeo y adultos $y$ huevos de la psila del peral
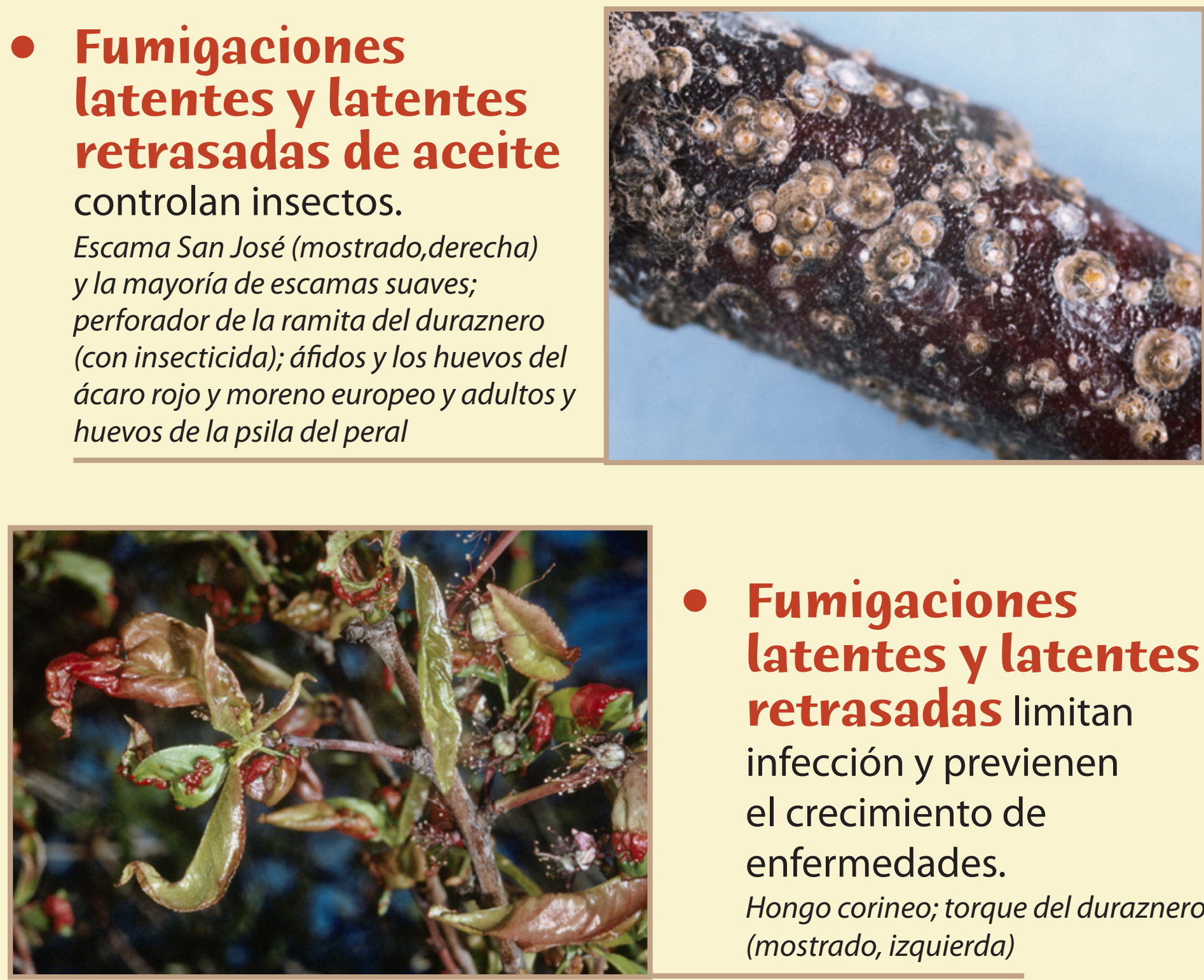

- Fumigaciones latentes y latentes retrasadas limitan infección y previenen el crecimiento de enfermedades. Hongo corineo; torque del duraznero (mostrado, izquierda) 